\section{Comparative Analysis of Generation Z Era Students' Overall Grades and Course Satisfaction of a Basic Floral Design Course Taught Fully Face-to-face versus an Online Hybrid Format}

\author{
Coleman L. Etheredge ${ }^{1}$ and Tina M. Waliczek ${ }^{2}$
}

ADDITIONAL INDEX WORDs. floriculture, higher education, horticulture, hybrid curriculum, teaching methods

Summary. As Generation Z (born 1995-2012) students replace Millennial (born 1981-94) students on college campuses, instructors may begin to evaluate and structure their courses based on how this new generation best learns. Generation $\mathrm{Z}$ students were exposed to such things as the internet, smart phones, personal computers, and laptops since infancy and, hence, are very comfortable with technology and multitasking. The purpose of this study was to compare students' overall grades and perceptions of the course and instructor in a face-to-face vs. an online/hybrid basic floral design course taken by a majority Generation $\mathbf{Z}$ student population. The face-to-face course consisted of live lectures that met twice per week for $50 \mathrm{~min}$ at an assigned time; reading materials and standard lecture slides were used. The hybrid course had content placed online within weekly modules and released to students in an asynchronous manner each Monday. Both versions of the course had a face-to-face laboratory that met once per week. Comparisons of grades between the face-to-face and hybrid course formats were made using analysis of variance tests. A Mann-Whitney $U$ test was used to determine if there were statistically significant differences in the way students in each course format answered the end of semester course and instructor evaluation survey. Of those that took the course, a majority [466 $(98.3 \%)]$ was between the ages 18 and 24 years, within the Generation $Z$ era. When comparing grades within this group, it was found students in the hybrid course received more A and B letter grades overall [223 (91\%)] compared with the students of the same age range in the face-to-face course [198 (88.7\%)]. Overall, seniors and juniors scored higher grades in both the hybrid and face-to-face course when compared with the sophomore and freshmen within the same class. No significant difference was found between the face-to-face and hybrid students' responses to any of the 11 questions on the course and instructor evaluation survey. Results showed an overall high level of satisfaction (4.50) for both the face-to-face and hybrid format.

A s more Generation $\mathrm{Z}$ students enter higher education, colleges and universities are rethinking how to educate this new generation

Received for publication 9 June 2021. Accepted for publication 9 Aug. 2021

Published online 28 September 2021

${ }^{1}$ Department of Plant and Soil Sciences, Mississippi State University, Starkville, MS 39759

${ }^{2}$ Department of Agricultural Sciences, Texas State University, San Marcos, TX 78666

C.L.E. is an Assistant Professor.

T.M.W. is a Professor

C.L.E. is the corresponding author. E-mail: cle248@msstate.edu.

This is an open access article distributed under the CC BY-NC-ND license (https://creativecommons. org/licenses/by-nc-nd/4.0/).

https://doi.org/10.21273/HORTTECH04900-21
(Seemiller and Grace, 2016). Generation $\mathrm{Z}$ can be defined as people born between 1995 and 2012. This generation has also been referred to as the internet generation or iGen (Gabrielova and Buchki, 2021). Because people of this generation have been exposed to such things as the internet, smart phones, personal computer, and laptops since infancy, they are known to be very comfortable with technology and good at multitasking with a variety of sophisticated technology (Gabrielova and Buchki, 2021; Hariadi et al., 2016).

The first Generation Z students began graduating college in 2017. Research investigating how Generation $\mathrm{Z}$ college students learn found they were observers, preferring to view a video of someone completing a task rather than to read instructions explaining how the task is completed before attempting the same task themselves (Seemiller and Grace, 2016). Studies have found video modules transfer knowledge to students better than traditional face-toface situations (Dey et al., 2009). Generation $\mathrm{Z}$ students are also intrapersonal learners, preferring to work on assignments independently at their own pace (Seemiller and Grace, 2016). Intrapersonal learning is unique to Generation Z, most likely due to the individual nature in which technology and the internet is used (Seemiller and Grace, 2016).

Lack of classroom space is a common issue among many large public and private universities due to an increase in student enrollment in the past several decades (Sciarappa et al., 2016). The growth of student populations on university campuses is expected to create larger class sizes as well as increased transportation and parking issues (Sciarappa et al., 2016). About 19.7 million students attended colleges and universities in the United States in Fall 2020 (National Center for Education Statistics, 2020).

Online learning is quickly becoming a larger component in the field of education (Gleason and Greenhow, 2017). Many scholars agree hybrid learning, which combines face-to-face and online learning, is the most promising approach for increasing access to higher education, while maintaining student learning outcomes (Means et al., 2010). Hybrid courses may also be referred to as web-enhanced, blended, or mixed-mode learning (Hall and Villareal, 2015). In a hybrid course, portions of the curriculum content are delivered online with additional face-to-face instruction in traditional classrooms or laboratories (Gleason and Greenhow, 2017). When teaching a hybrid course, the online portion of the class can be taught in an asynchronous or synchronous instruction method. Asynchronous methods allow students to access the online material at any point in a week to view course content and finish assigned tasks. There is no live lecture video meeting component in an asynchronous class (Scheiderer, 2021). In a synchronous course, students are required to $\log$ into the class each week during a 
scheduled time and actively participate in the learning process with the instructor (Scheiderer, 2021).

The number of universities using hybrid courses is growing rapidly, allowing students more options when choosing distance education courses (Gleason and Greenhow, 2017). As of 2018, an estimated 6.9 million students were enrolled in a distance education course (National Center for Education Statistics, 2020). With advances in technologies, new models for hybrid education are now available (Gleason and Greenhow, 2017) in the classroom using such programs as a hybrid synchronous model, which gives online students the ability to attend face-to-face courses with other students physically present on-campus and in the classroom, through using such programs as Zoom (San Jose, CA) and WebEx (Milpitas, CA) (Roseth et al., 2013).

Hybrid courses help to make education more accessible to students by decreasing travel requirements for students, especially those who live in rural areas, thus reducing travel expenses and increasing convenience (Hall and Villareal, 2015; Yudko et al., 2008). Hybrid courses appeal to students who manage busy schedules and have multiple work and home responsibilities. They also allow colleges to reach a more diverse student demographic (Hall and Villareal, 2015; Woodworth and Applin, 2007).

In a 9-year case study comparing differences between a face-to-face and hybrid agricultural-horticultural course entitled, "Organic Farming and Gardening," few significant differences were found when comparing final grades and students' overall satisfaction (Sciarappa et al., 2016). Additional studies found students participating in either a face-to-face or a hybrid course attained comparable achievement and knowledge retention scores (Delialioglu and Yildirim, 2008). In another study comparing the effectiveness of an online floral design course to a face-to-face format, no difference in overall satisfaction of the course was found between the two formats. However, students taking the face-to-face format of the course had slightly higher overall grades when compared with the online students (Henss et al., 2006).

Due to the diversity of delivery formats, students' comfort level with technology, and the selection of instructional activities learning outcomes for a hybrid course can vary depending on the content attempting to be taught in a hybrid manner (Hall and Villareal, 2015). The expected learning outcomes of the individual course being taught in a hybrid format should be carefully considered first to determine whether a hybrid style teaching method can better prepare students to meet those goals (Hall and Villareal, 2015; Zhou et al., 2012). To maximize student satisfaction and performance, there is a need to determine which elements of a hybrid course increase these traits in students and to meet those outcomes in both online and face-to-face learning (Hall and Villareal, 2015; Paechter and Maier, 2010).

Online courses can come with disadvantages, students often perceive classes taught online as easier and take them merely out of convenience, this can lead to students falling behind in online courses due to lack of organization and self-discipline (Dumford and Miller, 2018; Henss et al., 2006). Failures in technology can result in student frustration, which in turn lowers their overall perceptions of the course. Additionally, issues with cheating and a feeling of isolation by students can arise (Dumford and Miller, 2018). Past research found freshmen college students received a disproportionate amount of $\mathrm{D}, \mathrm{F}$, and $\mathrm{W}$ letter grades in distant education classes when compared with face-to-face classes (Urtel, 2008). This could be due in part to freshmen not being fully comfortable with online technology or the associated challenges (Urtel, 2008).

The purpose of this study was to compare students' overall grades and perceptions of the course and instructor in a face-to-face vs. an online/hybrid basic floral design course taken by a majority Generation $\mathrm{Z}$ student base.

\section{Material and methods}

BASIC FLORAL DESIGN COURSE SAMPLE. The sample included students enrolled in the basic floral design course taught during the Spring and Fall 2019 semesters, as well as those enrolled during Fall 2020 semester and Spring 2021 semester. The course offerings were taught at Mississippi State University (Starkville) through the Department of Plant and Soil Sciences. The basic floral design class is a three-credit-hour course consisting of lectures and a required laboratory. The current instructor of the course has been teaching the class since 2015 and taught the course throughout the entirety of the study. The class has a maximum capacity of 126 students per semester. The basic floral design course is listed as a fine arts class at Mississippi State University and can be taken to satisfy the 3-h fine arts general elective requirement mandated in the university core curriculum for all students regardless of their major, therefore the class draws students from all majors and departments on campus.

Course CONSTRUCTION AND STRUCture. During the Spring and Fall 2019 semesters, the course was taught fully in person with no webassisted or online components. The course consisted of live lectures that met twice per week for $50 \mathrm{~min}$ at an assigned time, reading materials, and digital lecture slides (PowerPoint; Microsoft; Redmond, WA) lecture slides. Additionally, during this semester, a 2-h hands-on laboratory met once per week at an assigned time and was used in conjunction with the lecture. Students had access to past lecture slides throughout the entire semester for review and were given exam study guides 2 weeks before exams. All exams were taken during the assigned lecture time in person and monitored by the instructor. In the laboratory, students were instructed in methods to construct a different style of floral design each week by the instructor. Students followed step-by-step instructions while guided by the instructor. The instructor would assemble a design along with the students demonstrating each step of the design process.

During the Spring and Summer 2020 semesters, the course was transitioned to a hybrid format as COVID-19 precautions were implemented across the university. The course began to be taught as a fully hybrid floral design course Fall 2020 semester. Data during Spring and Summer 2020 transition semesters were not used in this study. Learning methods were modified from the conventional course to include online instruction and technology. All lectures were dubbed over with audio of the instructor presenting the lecture slides and were placed online along with all additional reading material. 
Quizzes, assignments, and exams were all converted to online format. Presentation videos for each week's floral design were created, in which the instructor assembled the floral design step by step while explaining how to assemble the design. Throughout the course of the semester students had access to past lecture slides and were given reviews for exams 2 weeks before each exam.

All online material was assembled using an online learning management system (LMS) (Canvas; Instructure, Salt Lake City, UT). An online proctoring service (Honorlock; Honorlock, Boca Raton, FL) linked through the LMS platform was used to proctor all exams to reduce instances of cheating. Through the proctoring system students were required to, activate their computer cameras while taking the exam, identify themselves by taking a photo before the exam and displaying their student identification to the camera, sweep the room in which they took the exam $360^{\circ}$ with the computer camera. Additionally, exams and quizzes were timed with only one attempt at completion given to encourage students to review the material. Online course content was placed into weekly modules on the LMS platform and released to students in an asynchronous manner each Monday. Students had until Sunday at midnight to complete all assigned weekly tasks. Students met with the instructor once per week during an assigned weekly laboratory time for $\mathrm{l} h$ to complete the weekly floral design. Face-to-face laboratory time was reduced from 2 to $\mathrm{lh}$ for the hybrid course because of online activities (watching weekly design videos, reviewing weekly flower lists, and taking flower identification quizzes) required of the students before attending laboratory. During laboratory time, the instructor did not assemble a design. Part of the laboratory procedure required students to watch the weekly design video before coming to their scheduled laboratory time. The instructor reiterated main points covered in the design videos and helped guide individual students through the process, when needed, as students constructed their own individual designs.

STUDENT AND COURSE EVALUATION. Student course comprehension was evaluated based on their overall grades. Grades included exams, laboratory grades, quizzes, and assignments and were evaluated based on a percent scale.

A standardized 11-question course and instructor evaluation survey was administered to the students at the end of the semester. Questions were answered on a five-point Likert type scale; answers ranged from "strongly disagree" to "strongly agree" (Likert, 1932). Examples of questions included, "I learned a great deal in this class," "The presentation of course content (lectures, web materials, and/or discussions, etc.) helped me learn in this class," and "The instructor conveyed the course content in an effective manner" (Mississippi State University, 2021).

Data Analysis. Data were analyzed using descriptive and frequency statistics. Comparisons of grades within the two class formats were made using analysis of variance (ANOVA) tests. A Mann-Whitney $U$ test was used to determine if there were statistically significant differences in the way students in the two different course formats answered the end of semester course and instructor evaluation survey.

\section{Results and discussion}

During the testing period, a total of 474 students completed the basic floral design course, of which 228 took the course face-to-face and 246 took the course in an online hybrid format.

An ANOVA test compared overall final course grades, student classification, gender, and age of the students in the face-to-face and hybrid courses. A difference was found between the face-to-face and hybrid course formats' overall final grades $(P=0.042)$ and among various student classifications $(P=0.026)$ (Table 1$)$. Frequency tests determined where overall grade differences occurred within each group (Table 2). It was found students in the hybrid course on average received the letter grade of A and B [223 (91.7\%)] more often compared with the face-toface students [203 (89.0\%)] (Table 1).

Overall, fewer freshmen enrolled in the hybrid course than the face-toface course. The roll out of the hybrid course coincided with the COVID-19 pandemic, which slowed overall new freshmen entering universities. Overall, Fall 2020 enrollment for Mississippi's eight public universities was at 77,154 compared with 77,894 students enrolled in Fall 2019, which is a decrease of around 1.0\% (Alsup, 2020). Data collected by the Office of Institutional Research and Effectiveness at Mississippi

Table 1. Analysis of variance and frequency comparison of students' overall grades, classification, gender, and age in the study comparative analysis of Generation $\mathrm{Z}$ era students' overall grades and course satisfaction of a basic floral design course taught fully face-to-face versus an online hybrid format.

\begin{tabular}{|c|c|c|c|c|c|c|c|}
\hline & \multicolumn{2}{|c|}{ Face-to-face ${ }^{z}$} & \multicolumn{2}{|c|}{ Hybrid $^{y}$} & \multirow[b]{2}{*}{ df } & \multirow[b]{2}{*}{ F } & \multirow[b]{2}{*}{$P$} \\
\hline & (no.) & $(\%)$ & (no.) & $(\%)$ & & & \\
\hline Grade $^{x}$ & & & & & 4 & 4.17 & $0.042 *$ \\
\hline A $(90 \%$ to $100 \%)$ & 137 & 60.1 & 187 & 76.0 & & & \\
\hline $\mathrm{B}(80 \%$ to $89 \%)$ & 66 & 28.9 & 39 & 15.9 & & & \\
\hline $\mathrm{C}(70 \%$ to $79 \%)$ & 19 & 8.3 & 7 & 2.8 & & & \\
\hline $\mathrm{D}(60 \%$ to $69 \%)$ & 2 & 0.9 & 8 & 3.3 & & & \\
\hline $\mathrm{F}(0 \%$ to $59 \%)$ & 4 & 1.8 & 5 & 2.0 & & & \\
\hline Classification & & & & & 3 & 5.01 & $0.026^{*}$ \\
\hline Freshmen & 22 & 9.6 & 14 & 5.7 & & & \\
\hline Sophomore & 90 & 39.5 & 75 & 30.5 & & & \\
\hline Junior & 50 & 21.9 & 79 & 32.1 & & & \\
\hline Senior & 66 & 28.9 & 78 & 31.7 & & & \\
\hline Gender & & & & & 1 & 2.66 & 0.103 \\
\hline Female & 187 & 82.0 & 215 & 87.4 & & & \\
\hline Male & 41 & 18.0 & 31 & 12.6 & & & \\
\hline Age (years) & & & & & 2 & 0.01 & 0.893 \\
\hline $18-24$ & 223 & 97.8 & 243 & 98.8 & & & \\
\hline $25-29$ & 5 & 2.2 & 1 & 0.4 & & & \\
\hline $30+$ & 0 & 0.0 & 1 & 0.4 & & & \\
\hline
\end{tabular}

${ }^{\mathrm{z}}$ Total number of face-to-face students $(\mathrm{n}=228)$

${ }^{\mathrm{y}}$ Total number of hybrid students $(\mathrm{n}=246)$.

${ }^{\mathrm{x}}$ ANOVA data runs horizontal while frequency statistics appear vertically.

*Statistically significant at the 0.05 level. 
Table 2. Frequency tests comparing overall letter grades based on student classification, gender, and age in the study comparative analysis of Generation $\mathrm{Z}$ era students' overall grades and course satisfaction of a basic floral design course taught fully face-to-face versus an online hybrid format.

\begin{tabular}{|c|c|c|c|c|c|c|c|c|c|c|c|c|c|c|c|c|c|c|c|c|}
\hline & \multicolumn{10}{|c|}{ Face-to-face ${ }^{\mathrm{z}}$} & \multicolumn{10}{|c|}{ Hybrid $^{y}$} \\
\hline & \multicolumn{2}{|c|}{ A } & \multicolumn{2}{|c|}{ B } & \multicolumn{2}{|c|}{$\mathrm{C}$} & \multicolumn{2}{|c|}{ D } & \multicolumn{2}{|c|}{$\mathbf{F}$} & \multicolumn{2}{|c|}{ A } & \multicolumn{2}{|c|}{ B } & \multicolumn{2}{|c|}{ C } & \multicolumn{2}{|c|}{ D } & \multicolumn{2}{|c|}{$\mathbf{F}$} \\
\hline & (no.) & $(\%)$ & (no.) & $(\%)$ & (no.) & $(\%)$ & (no.) & $(\%)$ & (no.) & $(\%)$ & $(\mathbf{n})$ & $(\%)$ & (no.) & $(\%)$ & (no.) & $(\%)$ & (no.) & $(\%)$ & (no.) & $(\%)$ \\
\hline Freshmen & 11 & 50.0 & 9 & 40.9 & 2 & 9.1 & 0 & 0.0 & 0 & 0.0 & 9 & 64.3 & 0 & 0.0 & 0 & 0.0 & 1 & 7.1 & 4 & 28.6 \\
\hline Sophomore & 52 & 57.8 & 27 & 30.0 & 8 & 8.9 & 2 & 2.2 & 1 & 1.1 & 51 & 68.0 & 16 & 21.3 & 3 & 4.0 & 4 & 5.3 & 1 & 1.3 \\
\hline \multicolumn{21}{|l|}{ Gender } \\
\hline Female & 117 & 62.6 & 54 & 28.9 & 12 & 6.4 & 2 & 1.1 & 2 & 1.1 & 168 & 78.1 & 30 & 14.0 & 6 & 2.8 & 6 & 2.8 & 5 & 2.3 \\
\hline Male & 20 & 48.8 & 12 & 29.3 & 7 & 17.1 & 0 & 0.0 & 2 & 4.9 & 19 & 61.3 & 9 & 29.0 & 1 & 3.2 & 2 & 6.5 & 0 & 0.0 \\
\hline \multicolumn{21}{|l|}{ Age (years) } \\
\hline $18-24$ & 135 & 60.6 & 63 & 28.3 & 19 & 8.5 & 2 & 0.9 & 4 & 1.8 & 184 & 75.7 & 39 & 16.0 & 7 & 2.9 & 8 & 3.3 & 5 & 2.1 \\
\hline $25-29$ & 2 & 40.0 & 3 & 60.0 & 0 & 0.0 & 0 & 0.0 & 0 & 0.0 & 1 & 100.0 & 0 & 0.0 & 0 & 0.0 & 0 & 0.0 & 0 & 0.0 \\
\hline
\end{tabular}

${ }^{\mathrm{z}}$ Total number of face-to-face students $=228$.

${ }^{\mathrm{y}}$ Total number of hybrid students $=246$.

State University indicates 227 fewer freshmen enrolled at Mississippi State University in Fall 2020 (3323 new freshmen) than in Fall 2019 (3500 new freshmen) (Mississippi State University, 2020). Additionally, lower classmen typically have a later class registration date than upper classmen, which potentially could have made it more difficult for freshmen and sophomore to register for the class before all seats were filled.

Both females [198 (92.0\%)] and males [28 (90.3\%)] scored the letter grade of A or B in the hybrid course more often when compared with females [171 (91.4\%)] and males [31 (78.0\%)] in the face-to-face course (Table 2).

Of those who took the course, a majority [466 (98.3\%)] were between 18 and 24 years of age; Generation Z era (Table 1$)$. When comparing overall grades within this group it was found students in the hybrid course received more A and B letter grades overall [223 (91\%)] than students of the same age range in the face-to-face course $[198(88.7 \%)]$ (Table 2).

Overall, seniors and juniors scored higher grades in both the hybrid and face-to-face course when compared with the sophomore and freshmen within the same class (Table 2). While seniors and juniors [104 (89.6\%) combined A and B letter grades] did just marginally better in the face-to-face class when compared with sophomore and freshmen [99 (88.3\%) combined $A$ and $B$ letter grade], seniors and juniors [150 (95.5\%) combined A and B letter grades] in the hybrid class received a final score of $A$ and $B$ much more frequently than sophomores and freshmen [76 (85.3\%) combined A and B letter grades] (Table 2).

More juniors and seniors [157 $(63.8 \%)$ combined juniors and seniors] and fewer sophomores and freshmen [89 (36.2\%) combined sophomores and freshmen] took the hybrid course when compared with those that took the face-to-face course [116 (50.8\%) combined juniors and seniors] vs. [112 $(49.2 \%)$ combined sophomore and freshmen] (Table 1). The fact more upper-class students took the hybrid course than took the face-to-face course may partially account for why the hybrid courses overall final grades were slightly higher when compared with the faceto-face course. Past research has found junior and senior college students exhibit greater readiness for self-directed learning, online communication, and have a higher motivation for learning when compared with freshmen and sophomore college students (Hung et al., 2010). The higher grades in the hybrid course may also be partially due to students being able to review lectures dubbed over with audio by the instructor throughout the entire course while the lecture slides available to the students throughout the entire semester in the face-to-face course did not have audio dubbed over the slides.

These findings differ from a past study comparing an online and faceto-face floral design course, which found students in the traditional section of the course scoring slightly higher overall (Henss et al., 2006). This disparity may partially be due to past studies investigating college students were conducted in the early to mid-2000s and investigated Millennial (born 1981-94) and not Generation $\mathrm{Z}$ students. Millennials have been found to be more collaborative in nature and have a teamwork-oriented approach to learning, which differs drastically from the preferred learning approaches of Generation Z students (Seemiller and Grace, 2016). The hybrid course in this study was structured in a manner known to be more conducive to Generation Z students' preferences for learning, such as using video-based learning and allowing a self-directed pace. This may partially account for the higher scores in these results (Dey et al., 2009; Seemiller and Grace, 2016).

The course and instructor evaluation survey was offered to students through the LMS platform at the end of the semester. Students were sent a standardized e-mail by the university at the end of the semester notifying them when the survey was available. The course instructor also sent a reminder e-mail, informing students of the survey and the importance of completing it. In total, 108 students completed the end of semester course evaluation survey in the face-to-face course and 91 in the hybrid course. Due to the relatively low response rate the results 
Table 3. Mann-Whitney $U$ test comparing end-of-year course evaluation scores between a face-to-face floral design course format and a hybrid style course format in the study comparative analysis of Generation $\mathrm{Z}$ era students' overall grades and course satisfaction of a basic floral design course taught fully face-to-face versus an online hybrid format.

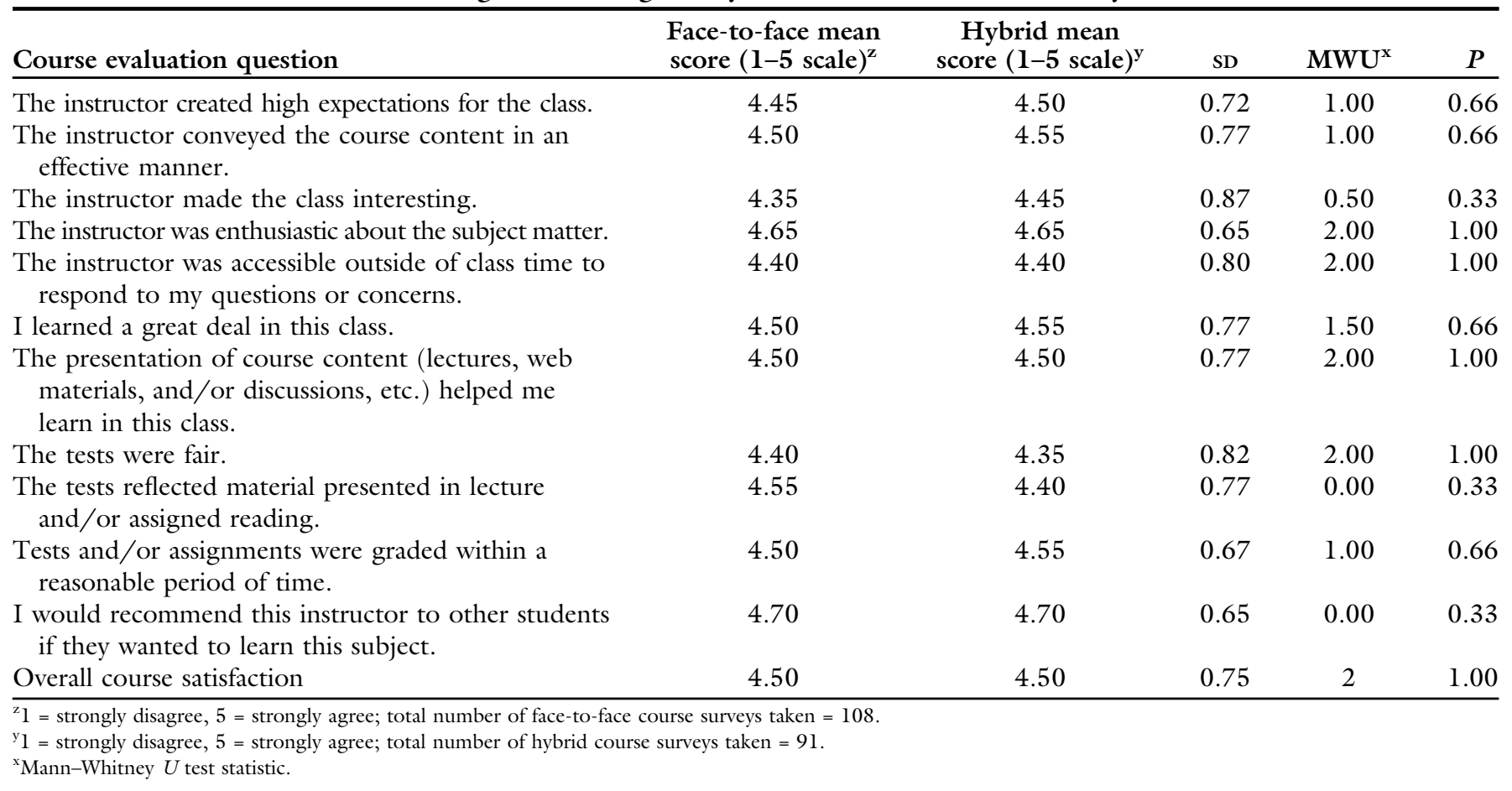

of the course and instructor evaluation survey could vary when comparing to a larger sample population.

No difference was found between the face-to-face and hybrid students' responses to any of the 11 questions on the course and instructor evaluation survey. Frequency statistics were used to determine the overall mean response for each survey question (Table 3). Question scores could range from 1 (strongly disagree) to 5 (strongly agree). A mean overall course satisfaction score was found to be 4.50 for both of the course formats, indicating an overall high level of satisfaction for both the face-to-face and hybrid course (Table 3 ). These findings support past research investigating the comparison of overall satisfaction of students taking an online floral design course vs. a face-to-face course, which also found no difference in overall course satisfaction between the two formats (Henss et al., 2006).

\section{Conclusions}

The findings indicate the course format did not appear to matter to the students' overall course or instructor satisfaction. Both course formats were rated as having the same level of high satisfaction. No difference was found when comparing the age and gender of student that took the face-to-face course vs. the hybrid format. Students in the hybrid course scored slightly higher grades when compared with students in the face-to-face course. While these findings differ slightly from past research, this could be due in part to a new generation of students that has become more familiar with the technology compared with previous generations. This familiarity with technology is due to their exposure to the internet, computers, laptops, smart phones, and other technological devices since infancy (Gleason and Greenhow, 2017). This could also be due in part to improvements and new development of technologies used in the education system in recent years (Gleason and Greenhow, 2017; Roseth et al., 2013; Scheiderer, 2021). Due to a lifelong familiarity with technology and the way in which cellphone and computer use are most often solitary practices, Generation $\mathrm{Z}$ students have developed a more unaccompanied observational approach to learning than in the past. The overall higher final grades in the hybrid course may also be due in part to more upperlevel students taking the hybrid course in response to fewer new freshmen entering college during the COVID19 pandemic (Alsup, 2020).

The fact that current college students are so well adapted to online technology and that the overall satisfaction of the course was viewed similarly regardless of whether it was taught in a face-to-face or online format, indicated a basic floral design course could be taught in an online hybrid format to potentially increase the overall understanding of the course, so long as instructors are building content while keeping in mind how best Generation $\mathrm{Z}$ students learn.

\section{Literature cited}

Alsup, B. 2020. MSU, USM see increased enrollment as state numbers decline. 13 May 2021. <https://www.djournal.com/ news/education/msu-usm-see-increasedenrollment-as-state-numbers-decline/article 9lc6bl7e-celd-58e8-8402-d937ecdf7613. html $>$.

Delialioglu, O. and Z. Yildirim. 2008. Design and development of a technology enhanced hybrid instruction based on $\mathrm{MO}$ LTA model: Its effectiveness in comparison to traditional instruction. Comput. Educ. 51:474-483, https://doi.org/10.1016/j. compedu.2007.06.006.

Dey, E., H. Burn, and D. Gerde. 2009. Bringing the classroom to the web: Effects of using new technologies to capture and deliver lectures. Res. High. Educ. 50:377-393, https://doi.org/10.1007/ S11162-009-9124-0. 
Dumford, A.D. and A.L. Miller. 2018. Online learning in higher education: Exploring advantages and disadvantages for engagement. J. Comput. High. Educ. 30:452-465, https://doi.org/10.1007/ s12528-018-9179-z.

Gabrielova, K. and A.A. Buchki. 2021. Here comes Generation Z: Millennials as managers. Bus. Horiz. 64:489-499, https://doi. org/10.1016/j.bushor.2021.02.013.

Gleason, B. and C. Greenhow. 2017. Hybrid learning in higher education: The potential of teaching and learning with robot-mediated communication. Online Learning J. 21:158-176.

Hall, S. and D. Villareal. 2015. The hybrid advantage: Graduate student perspectives of hybrid education courses. Intl. J. Teach. Learn. High. Educ. 27:69-80.

Hariadi, M.J., S. Dewiyani, and P. Sudarmaningtyas. 2016. Development of web-based learning application for Generation Z. Intl. J. Evaluation Res. Educ. 5: 60-68.

Henss, S.R., J.M. Zajicek, and R.D. Lineberger. 2006. A comparison of student grades, floral design laboratory skill scores, and course satisfaction on traditional online sections of a university floral design course. HortTechnology 16:626-632, https://doi. org/10.21273/HORTTECH.16.4.0626.

Hung, M.L., C. Chou, C.H. Chen, and Z.Y. Own. 2010. Learning readiness for online learning: Scale development and student perceptions. Comput. Educ. 55:
1080-1090, https://doi.org/10.1016/j. compedu.2010.05.004.

Likert, R. 1932. A technique for the measurement of attitudes. Arch. Psychol. 22:140-155.

Means, B., Y. Toyama, R. Murphy, M. Bakia, and K. Jones. 2010. Evaluation of evidence-based practices in online learning: A meta-analysis and review of online learning studies. 25 Mar. 2021. <https:// repository.alt.ac.uk/629/1/US_DepEdu_ Final_report_2009.pdf>.

Mississippi State University. 2020. Enrollment data. 8 July 2021. <https://ir.ms state.edu/research/enrollment_data.php $>$.

Mississippi State University. 2021. Online course evaluations. 25 Mar. 2021. $<$ https://www.ctl.msstate.edu/program sandservices/onlinecourseevalutions $/>$.

National Center for Education Statistics. 2020. Back to school statistics. 24 Mar. 2021. <https://nces.ed.gov/fastfacts/ display.asp? $\mathrm{id}=372>$.

Paechter, M. and B. Maier. 2010. Online or face-to-face? Students' experiences and preferences in e-learning. Internet High. Educ. 13:292-297, https://doi.org/ 10.1016/j.iheduc.2010.09.004.

Roseth, C., M. Akcaoglu, and A. Zellner. 2013. Blending synchronous face-to-face and computer supported cooperative learning in a hybrid doctoral seminar. TechTrends 57:54-59, https://doi.org/ 10.1007/s11528-013-0663-z.
Scheiderer, J. 2021. What's the difference between asynchronous and synchronous learning? 25 Mar. 2021. <https://online. osu.edu/resources/learn/whats-differencebetween-asynchronous-and-synchronouslearning $>$.

Sciarappa, W.J., V. Quinn, and D.L. Ward. 2016. Comparing conventional, hybrid, and distance learning courses in horticulture. HortTechnology 26:677682, https://doi.org/10.21273/HORT TECH03377-16.

Seemiller, C. and M. Grace. 2016. Generation $\mathrm{Z}$ goes to college. Jossey-Bass, San Francisco, CA.

Urtel, M.G. 2008. Assessing academic performance between traditional and distance education course formats. Educ. Tech. Society 11:322-330.

Woodworth, P. and A.G. Applin. 2007. A hybrid structure for the introductory computers and information technology course. J. Comput. Sci. Coll. 22:136144, https://doi.org/10.1007/978-3642-39750-9_33.

Yudko, E., R. Hirokawa, and R. Chi. 2008. Attitudes, beliefs, and attendance in a hybrid course. Comput. Educ. 50: 1217-1227, https://doi.org/10.1016/j. compedu.2006.11.005.

Zhou, W., E. Simpson, and D.P. Domizi. 2012. Google docs in an out-of-class collaborative writing activity. Intl. J. Teach. Learn. High. Educ. 24:359-375. 